\title{
Improved Forage Production in Ethiopia: Utilization, Challenges and Prospects for Adoption: A Review
}

\author{
Muluye Fekade
}

\begin{abstract}
There are several factors that hinder the productivity of livestock in Ethiopia of which nutrition contributes the largest share. The quality and quantity of feed are poor challenging livestock production. Nowadays, due to the rapid increase of human population and increasing demand for food, grazing lands are steadily declining by being shifted to arable lands for crop production. As a result, food crop residues are providing a considerable quantity of dry season feed in most farming areas of the country. However, the feeding value of crop residues is very poor. One way to alleviate this problem is supplementation of crop residue through the use of improved forage and fodder trees. Research and development agents have been testing and identifying promising forages that are suitable for pasture rehabilitation in a wide range of agro-ecological zones besides animal feeding. The use of forage legumes have a paramount role resulted in increasing soil nitrogen available for food crops because of their ability to fix nitrogen. Moreover, multipurpose browse trees and shrubs serve as fuel wood resource. Improved forage legumes and browse species provides protein which enhances the feed resources available for livestock. The major impediments of improved forages production in different parts of the country are ecological deterioration, overgrazing, land tenure, border conflict, drought, weed and bush encroachment, lack of seed and planting materials. The diverse topography coupled with environmental heterogeneity offers favorable environments for pasture species, herbaceous legumes and browse trees/shrubs. Hence, assessing the conditions, challenges, opportunities and recommendations of improved forage production is very imperative for effective and efficient utilization of these feed resources to boost the productivity of the livestock sector in the country.
\end{abstract}

Keywords: improved forages, nutrition, crop residues, challenges, utilization

DOI: $10.7176 / \mathrm{JBAH} / 9-21-02$

Publication date: November $30^{\text {th }} 2019$

\section{Introduction}

The national income of Ethiopia is mainly dependent up on Agriculture by which the livestock sub- sector plays a significant role on it (Alemayehu 2012) and at a household levels as well (Gebreegziabher and Tsegay 2016). Although livestock has a vital role in the household and national economy of the country, current contribution of this subsector is below its potential due to various factors. Reports by ILRI (2010); Behnke and Menagerie (2011) indicated that the overall livestock sector, such as cattle, sheep, goats, equine and poultry contributes about 15 to $17 \%$ of gross domestic product (GDP) and 37 to $87 \%$ of the household incomes. Such very low productivity is attributable to different constraints like poor nutrition, diseases, genetic makeup and environment of which poor nutrition takes its large effect. In many parts of the country, animals are kept on poor quality natural pasture that commonly occur on permanent grasslands, roadsides, pathways and spaces between cropped plots. Moreover, the main livestock feed resources accessible in Ethiopia are natural pastures, crop residues and aftermath grazing (Adugna 2008) and (Getnet 2012). However, these feed resources are very low in quality having high fibre, with low to moderate digestibility and low levels of nitrogen (Tsige-Yohanes 2000), which might be linked with a low voluntary intake, thus resulting in inadequate nutrient supply, low productivity and even weight loss. Livestock feed is greatly in short supply particularly latter in the dry season and of poor in quality. On the other hand, avoiding the feed resources from the fields results in decreasing organic matter content found in the soil which in turn degrades soil structure and increases erosion (Alemayehu et al. 2016). This condition calls for integration of improved forages that could have several advantages over conventional feed resources available. It contributes much to supplement low quality feed resources such as crop residues and pasture roughages there by overcoming the dry season constraints affecting livestock production. Forages have much potential within the farming systems of Ethiopia. Moreover, forages not only help to slow land degradation by improving soil fertility, they also help to combat soil loss through erosion. In addition to improving the soil fertility, a high quality animal feed is being produced. This increase in animal nutrition results in increased manure production from the animals, which in turn adds nutrients to the soil. The potential that forages hold to help improve the soil quality and fertility can help the farmer maintain soil quality with low external inputs (Gary A. Sullivan 2001). Several researches have been conducted regarding to improved forage production, adoption and utilizations in different areas of the country. The main focus of this paper is therefore to review such utilizations, challenges, prospects and recommendations on improved forage production in Ethiopia.

\section{Status of farmers' perception towards improved forage adoption}

Improved forage Adoption as Zakarias (2016) described it, is the decision to use a new technology of improved 
forages, method, and practice by a firm, a farmer, or reflects a farmer's decisions to include a new forage technology into the production process of the farming system. Then, farmers will adopt only those technologies that fit their needs. This can provide an opportunity for increasing production and income of smallholder farmers. Several efforts have been made to increase agricultural productivity by researchers and extension staffs in Ethiopia through promoting a technological package. However, farmers are rarely adopting complete packages due to various factors such as awareness problem, capital scarcity and risk considerations (Zakarias 2015).

According to Mokoya et al. (2008), over many decades, Ethiopia has cultivated various improved forage species such as Sesbania, Leucaena, and Calliandra and Tree Lucerne, for supplementary feeding of livestock and soil improvement. In spite of the significant development efforts undertaken and the apparent benefits obtained, the number of farmers planting these trees were very low. The same authors stated that understanding farmers' perception about the feeding and other alternative role of fodder trees at the farmland and constraints to adoption and growing of multipurpose fodder trees will contribute to better understanding of how and which innovations should be introduced.

Zubair et al. (2012) in their study indicated that the success of any demonstrated intervention completely relies upon the results of given technology. If an intervention produce positive results then the fates of its introduction remains high otherwise vice versa. With many ways of integrating forages into the cropping systems, it is hoped that individual farmers under various situations may be able to find a method of integration that suits their interests and land requirements (Gary 2001). Different investigations noted that most farmers in Ethiopia were aware of the possibility of growing and utilizing improved forages and also of the possible benefits earned. However, being aware about an innovation does not necessarily lead to adoption of improved forage varieties unless applied in practice.

\subsection{Improved forages production practice}

Many researchers have been conducted with respect to improved forage production practices in various parts of the country. In relation to this view, the main improved forage species widely produced in different areas of Ethiopia are not uniformly distributed as a result of a numbers of factors. According to a recent research by Workye et al.(2018) elephant grass, vetch, oat, Rhodes grass, sesbania, dasho grass and leucaena with their decreasing order of availability were the major improved forages in Libokekem district. The major forage species widely distributed in the Shashogio district, as Feleke et al. (2015) observed, were similarly stated as with the former authors but there has been exceptions such as vetch and oat, not indicated in his study. In another study, Shiferaw et al. (2018) in his finding elucidated that there was a relatively good status of improved forage production by farmers in Mecha and Achefer districts, natural resource areas of west Gojam zone. The author argued that integration of improved forages with the farming system has been promoted in those areas for a long time. Based on the findings of Workye et al.(2018) and Feleke et al. (2015), the majority of farmers were not cultivating improved forage, only a small area of land was allocated for forage development. This poor practice of forage development might be challenged by resource and technology limitations. A study conducted in north east highlands of Ethiopia showed that the resource endowment of households like farm size, livestock ownership and labor available had a positive and significant effect on the adoption of forage technologies (Beshir 2014). In any way, the findings of those authors were contrarily stated by Shiferaw et al. (2018).

\subsection{Purpose and utilization of improved forages}

Making use of improved forage varieties has several advantages. The most important contribution of improved forages is their direct effect on livestock production. It had good feeding value related to nutrient contents and digestibility. Better animal performance can be obtained from high protein and energy because milk and other products increase their nutrients flourish for the neonate and human nutrition (Mengistu 2012) and (Endalew et al. 2016). Not only improving animal nutrition resulting in higher producing livestock; it also compliments crop production by maintaining soil fertility through nitrogen fixation. While grazing depletes the fertility of the land, forage growing improves soil health. For instance, intercropping species like maize and Lablab or coffee and Desmodium is more advantageous than growing one crop alone (Etsubdink 2012). According to Gebreegziabher and Tsegay (2016) and Workye et al.(2018), improved forage cultivation practiced for various purposes such as source of animal feed, soil conservation, crop rotation, wind break, fence and for fuel. In Ethiopia, amongst the purpose of forage production, animal feeding and soil and water conservation are accounted the largest share. Bezabih et al. (2016) noted that soil conservation can improve and maintain soil fertility. It also minimizes diminishing grazing pastures for crop cultivation. Using improved forage production for soil conservation might be due to the recent campaign to soil and water conservation in the country. In areas of Lay-Armachuho district of Amhara region, in the north-western highlands of Ethiopia, and Sidama district of Southern region, in the southern highlands of Ethiopia, farmers' preference criteria encompass multiple intentions beyond feed value and soil rehabilitation (Mekoya et al. 2008). 


\subsection{Improved forage production strategies}

Natural grazing and browse, crop residues, improved pasture, forage crops and agro-industrial by-products are the main livestock feed resources in Ethiopia. Grazing lands have been degrading due to the demand for high pressure on land resources from increasing populations and greater cropping intensity. Although crop residues serve as a feed resource for livestock, it is poor in quality which could not provide the nutritional requirements of the animal. Removing them from the fields also reduce organic matter content in the soil which degrades soil structure and increases the erodibility of cropped land. Furthermore, industrial by-products are too expensive for smallholder farmers to afford. The prevailing feed shortages in different agro-ecological zones can be overcome by producing improved forages. In due regard, Alemayehu (2006) indicated that improved feed supply is possible if backyard forage production, under-sowing, over sowing and growing improved pasture and forages are widely adopted.

Forage and pasture development strategies have been promoted widely into the crop-livestock system, traditional grazing areas, and around homesteads, within soil and water conservation structures and under plantation crops and forestry (Alemayehu 2006).

\subsubsection{Backyard forage production}

This is a strategy by which small plots and hedges of productive forage and browse planted within house compounds and around their boundaries. It is the most important initial strategy since it is developed in the farmer's household, and is very suitable for intensive feeding. Since house compounds are highly fertile, it supports a successful establishment of backyard forage. This strategy has a major impact in exposing farmers to the management and productivity of new species and also provides a seed bank to help establish new plantings for other forage strategies.

Woody leguminous browse species are particularly convenient to this strategy because of their multipurpose benefits (i.e. provides forage and fuel wood, used as shelter, increased privacy, constructions, and hive) and fast growth rates. According to Alemayehu (2002) tall growing tropical grasses are also convenient to backyard forage development. Backyard forages can be cut and carried to intensify (tethered or housed) animals, or for dry season use, it can be cut and conserved in mixes with crop residues and natural pasture hay or roughages. Leucaena, sesbania, pigeon pea and Tree Lucerne, whereas Greenleaf, silver leaf, alfalafa, vetch and vernano stylo herbaceous forage legumes are the most commonly used backyard tree legumes in Ethiopia. Similarly, grasses including Rhodes grass, elephant grass, panicum, phalaris and oats can be used as backyard forage.

This strategy provides an opportunity to reach large numbers of farmers very quickly. Forage seedlings or sets can be planted in any pattern to suit the needs of the household but simple boundary hedges/shelter belts or forage blocks are the most widely accepted designs for backyard forage plantations.

\subsubsection{Under-sowing and inter-planting}

Training by the Netherlands organization for extension workers in Ethiopia indicated that this strategy involves the establishment of forage species in an annual crop or perennial plantation. It provides the most suitable approach to rapidly increasing on-farm forage supplies over a large number of farmers. The use of legumes in this system will contribute to the improved fertility and structure of cropping soils. The strategy is more acknowledged in its convenience for the production of tall growing cereals such as maize, sorghum or millet but also works with other cropping systems. Large quantities of high quality forage for utilization by either post-harvest grazing or cut and carry systems can be produced by under sowing with legumes. The under sown forage is important in protecting the soil from erosive rains, can contribute nitrogen for the food crop, and balances the forage value of crop residues to increase its feeding value. Sprawling and climbing legumes are convenient to this strategy. In addition, tree crops and some vegetables can also be under sown or inter planted with leguminous forages. The establishment of annual or perennial legumes under tree crops is a reliable strategy, which is highly valued by farmers.

It is very crucial that forages should be under sown at the time of final weeding, where crop weeding practices are very thorough. Hence, avoids any risk of the under sown legume competing seriously with the cereal crop but often means that the legumes have insufficient time to produce ripe seed prior to crop harvest. Where little weeding practices, under sowing should coincide with an earlier weeding. In such a way sufficient legumes survive any subsequent weeding to provide ample seeding capacity prior to crop harvest. Early maturing cereals are generally suitable for better forage production because they compete with the under sown forage legume for only a short period of the growing season. Good stands of under sown legumes produce 2,500 to 3,000 $\mathrm{kg}$ dry matter per ha from one cut in farmers' fields (Robertson 1990).

\subsubsection{Contour forage strips}

These are broad based mixtures of herbaceous and tree legumes, and grasses planted on contour bunds or in narrow strips along the contour without any physical structures. It is a multipurpose strategy providing forage, shelter, soil stabilization and fuel wood. Moreover, its contribution goes towards soil conservation by directing ploughing along the contour and by reducing run-off down the slope. As a result, these increases infiltration and reduces soil erosion, particularly where a thick sward of grass or herbaceous legumes is included in the forage strip. This strategy is particularly successful when perennial, thick rooted grasses are mixed with woody leguminous species. 


\subsubsection{Forage crop production}

When farmers having sufficient land practice cropping rotation, they utilize a short-term forage crop. Short-term forage crops can be reliably introduced over a wide range of sites but are most appropriate for farmers who depend on dairy production for their income. Mixed annual leguminous species and cereals provide the best quantity and quality of forage in highland areas but in middle altitude and lowland areas, annual legume forages optimize forage production. Farmers are shifting towards perennial forage production strategies in Ethiopia because annual forage crops do not integrate livestock and cropping systems except where fallow is commonly used. In these areas fallow reduction strategies based on leguminous forage crops are appropriate. Oats and vetch have been cultivated well over a wide range of agro ecological zones, with oats showing a good adaptability in a relatively less fertile soils and poor drainage. Alfalfa does not persist under rain fed condition in Ethiopia whereas; lablab is very productive at a lower altitude even competing well with weeds. Oat/vetch and lablab strategies accepted by farmers, in particular where fattening or dairy enterprises are viable.

\subsubsection{Agroforestry}

This strategy is the combination of trees and agriculture in an integrated and sustainable farming system. Many of the strategies can be developed as agro forestry systems, especially contour forage banks and under-sowing of tree crops or forest plantations. It is particularly important for farmers with limited land resources. Because many agroforestry strategies include leguminous species, they are also attractive to farmers facing problems of declining soil productivity.

Various studies shows that productivity and forage value of agroforestry browse species are affected by the height and frequency of cutting. For example, Leucaena produces more DM at longer cutting intervals (more than 3 months) and moderate cutting height $(75$ to $100 \mathrm{~cm})$ than more severe defoliation. Similarly, total DM yield of Sesbania increased with increased cutting interval with the highest yields recorded at 8 week cutting intervals. The $100 \mathrm{~cm}$ cutting height gave maximum yields from 12 month old Sesbania. Pigeon Pea also gives maximum yields with a cutting frequency of about 8 weeks (Alemayehu 2002).

\subsubsection{Over sowing}

According to the forage extension manual prepared by Ministry of Agriculture, over sowing is the simplest of the forage development strategies and can be performed at very low cost. It referrers broadcasting or sowing improved forage seeds into common grazing lands, native pastures and degraded areas without any cultivation or other inputs. In this strategy, there is no attempt to modify grazing management and existing stocking rates should remain constant after over sowing.

It includes sowing roadsides and is suited to aerial seeding where very large areas are to be established. This strategy is most favored to pioneer legume species, which grow quickly and seed prolifically. Because of the low input nature of this strategy, incremental forage yields are not large but pioneer species having good grazing tolerance and natural seeding ability gradually colonize common areas and improve species composition available for grazing. A rapid natural spread of seed due to water movement, grazing animals and wind action can help very large areas of land to be developed. This strategy is more likely to provide long term advantages for the farmers if there is some grazing management group. The provision of seed and technical support for over sowing strategies is a sufficient incentive to encourage farmers.

\subsection{Challenges to improved forage adoption}

In Ethiopia, forage development strategy have been practiced long ago, but its adoption by the farming community has been very low because of various factors such as lack and unadoptable forage technologies, poor extension services, lack and high cost of planting materials, reluctance of most smallholder farmers and size of livestock ownership and farm size (Othill 1986) and (Alemayehu and Getnet 2012)and (Beshir 2014). However different, the highlands and lowlands hold similar constraints to adoption of forage technologies. Land shortage is one of the major factor to adoption in the Ethiopian farming system. This is a constraint because of unwilling farmers to take land away from cultivating food crops for improved forage production. With respect to this view, cereal crops are not affected by using one of the intercropping techniques or using niche areas (Teshome 2014). Land tenure is a challenge to farmers wanting to adopt long-term technologies for soil improvement and tree development since there might be uncertainty of tenure. Shortages of labor also play a vital role in whether farmers adopt forages or not. Labors are getting busy during the times when labor is required for forages by being already occupied by other fieldworks. Thus, labor constraints may continue to be a factor influencing the adoption of improved forages. Several researchers have been tried to identify lack of knowledge as a constraint for farmers which affect adoption. After having forages on their hands they do not know what is best to do with them or how to use them efficiently. Lessening the problem can be possible with the help of good extension services. It is well recognized that extension service is an important pillar in the transformation of subsistence agriculture to market oriented agriculture (Gebremedhin et al. 2006). Moreover, lack of adequate seed availability is also a constraint for the adoption of improved forages, which must be addressed and should not be overlooked. The other major factor affecting adoption by many farmers in Ethiopia is lack of capital to cover the up-front costs of developing certain forage 
technologies. The last constraint is that the generic technologies provided to farmers may be inappropriate for the individual farmers. If researchers fail to address the needs of farmers, they won't adopt because the technologies do not fit into the farming system (Gary 2001).

\subsection{Prospects for improved forages adoption}

According to Alemayehu, (2006), in the past few decades, various forages have been tested in different agro ecological zones. Considerable efforts have been made to test the adaptability of these crops under varying agro ecological conditions in different parts of Ethiopia. Consequently, selection of quite a number of useful forages for different agro ecological zones has been made to be possible. Improved forage crops are commonly useful for feeding dairy cattle (Alemayehu, 2006). However, there has been limited spontaneous adoption of improved pasture and forages due to land scarcity and crop-dominated farming systems as a result of increased human population. Alemayehu $(2002,2006)$ on the other hand noted that, there are several prospects for improved forage production. Integration of pasture and forage crops in the existing farming system is a good opportunity for the production of improved forages. Because of high demand for land resources and greater cropping intensity from populations growing at alarming rate, forage crops cannot be produced in sufficient quantities unless there is an integrated crop-livestock production system (Alemayehu 2002). As indicated in several literatures, livestock and cropping systems can be integrated in a number of ways, including agroforestry, intercropping and ley farming. Alemayehu (2006) stated that one of the best opportunities for highland farmers to use land efficiently will be through the introduction of pasture and forages in the farming system.

In addition to a higher yield and nutritional value gained from cultivated pastures, they have longer length of productive season, which provides an opportunity for dairy and fattening production to develop and use pasture and forage on a large scale (Alemayehu 2006). Besides, fodder trees and shrubs assists in increasing soil fertility, controlling soil erosion and providing firewood and timber. These legumes are well adapted to the current edaphic and grazing condition, they can be readily integrated into farming systems, and they retain their greenness and feeding value into the dry season (Alemayehu 2006). Furthermore, irrigation based forage production in the high irrigation potential an area of the country is a good prospect for dairy farmers. Small-scale traditional irrigation has been practiced for decades throughout the highlands; small streams are seasonally diverted for limited dry season cropping. This is a good opportunity to grow off-season pasture and forage crops. Medium- and large-scale schemes are of much more recent origin, mostly in the Rift Valley for cash crops. There is some irrigated forage in the Rift Valley growing lucerne/Rhodes mixture for commercial fattening and dairy farming. The potential for irrigated forage is untapped and still there is a great opportunity for producing seasonal and long-term irrigated pasture and forages (Alemayehu 2006).

Access to irrigation supplements moisture, which enables farmers to maximize agricultural production. Water is an essential resource for forage production; the amount and distribution of rainfall significantly determine the growth and production of improved forage. Irrigation access offers the chance for forage production to the farmers. Farmers having good access to irrigation, they can practice forage growth three times a year (Shiferaw et al.2018). Apart from this, the availability of several NGOs for the community can be taken as great opportunity for future expansion of the technology (Addisu et al. 2016).

\section{Conclusion and Recommendations}

One of the major bottlenecks to increase livestock production in Ethiopia is the shortage of feed for different livestock. Natural pasture, crop residues, and crop aftermath grazing are the main feed resources utilized by livestock in Ethiopia. These feed resources are low in quality characterized by high fibre, with low to moderate digestibility and low levels of nitrogen, which in turn linked with low voluntary intake, low productivity and even weight loss. In order to improve the shortage of livestock feed in crop livestock production system, it is important for farmers to integrate forage production in the farming system. The use of improved forages could have a much potential to alleviate such a problem associated with conventional feeds. Ethiopia has cultivated various improved forage species over decades. As part of producing improved forages in different parts of the country, great efforts have been made by many researchers and development agents. In general, even if use of improved forages has been practiced long ago, its adoption has faced many challenges of which shortage of land, poor extension services, unwillingness of most farmers and size of livestock ownership are common. On the other hand, there are future prospects for improved forages adoption such as integration of pasture and forage crops, long productive season of cultivated pastures, good adaptability of forages in different agro ecologies and so on. Previous studies by several researchers recommended that a large extension service delivery may be imperative to improve the production and adoption of improved forages for sustainable development in animal production.

\section{REFERENCES}

Addisu- Endalew, Firew -Tegegne, Getnet -Assefa (2016), “Constraints and Opportunities on Production and Utilization of Improved Forages in East Gojjam Zone, Amhara Region, Ethiopia: In the Case of Enebsie Sar 
Midr District". Journal of Biology, Agriculture and Healthcare. 6(9).

Adugna T. (2008), "Feed resources and feeding management: A manual for feed operators and development workers". Ethiopia Sanitary and Phytosanitary Standards and Livestock and Meat marketing Program (SPSLMM) Report. Addis Ababa, Ethiopia. 38pp.

Alemayehu et al. (2016), "Improved forage crops production strategies in Ethiopia: A review". Academic Research Journal of Agricultural Science and Research.

Alemayehu M and Getnet A. (2012), "Evaluation of forage seed production in Ethiopia". In: Getnet Assefa, Mesfin Dejene, Jean Hanson, Getachew Anemut, Solomon Mengistu And Alemayehu Mengistu (eds), Forage seed research and development in Ethiopia. Ethiopian institute of agricultural research, Addis Ababa, Ethiopia. Pp 15-32.

Alemayehu M. (2006), “Country pasture/forage resource profiles, Ethiopia”.

Alemayehu M. (2012), "Keynote address". In: Getnet Assefa, Mesfin Dejene, Jean Hanson, Getachew Anemut, Solomon Mengistu And Alemayehu Mengistu (eds), Forage seed research and development in Ethiopia. Ethiopia institute of agricultural research, Addis Ababa, Ethiopia. Pp 3-5.

Bahilu Bezabih, AbebayehuAticho, Tadesse Mossisaand Bayu Dume (2016), "The effect of land management practices on soil physical and chemical properties in Gojeb Sub-river Basin of Dedo District, Southwest Ethiopia". Journal of Soil Science and Environmental Management.

Behnke R, Menagerie F. (2011), The Contribution of Livestock to the Ethiopian Economy". Part II, IGAD Livestock Policy Initiative (LPI). Working Paper No. 0211.

Berhanu Gebremedhin; and Azage Tegegne (2006), "Improving Productivity and Market Success of Ethiopian Farmers Project (IPMS)". Commercialization of Ethiopian agriculture: extension service from input supplier to knowledge broker and facilitator. IPMS Working Paper 1. Nairobi (Kenya): ILRI.

Beshir H. (2014), " Factors Affecting the Adoption and Intensity of Use of Improved Forages in North East Highlands of Ethiopia". American Journal of Experimental Agriculture, 4(1):12-27.

Endalew A, Tegegne F, Assefa G. (2016), "Constraints and Opportunities on Production and Utilization of Improved Forages in case of Enebsie Sarmidr District, East Gojjam Zone and Amhara Region, Ethiopia”. Thesis. Woldia University, Woldia.

Etsubdink Tekalign (2014), "Forage seed systems in Ethiopia: A scoping study". ILRI Project Report. Nairobi, Kenya: International Livestock Research Institute (ILRI).

Feleke Assefa, Tsegaye Ano, Teshale Aba and Zehara Ebrahim (2015), "Assessment of improved forage types and their utilization in Shashogo Woreda, Hadiya zone, Southern Ethiopia". Global Journal of Animal Science. 3 (6):227-230.

Gary A. Sullivan (2001), "Forages: Looking at the Potential and the Pathways toward Adoption in the Ethiopian Farming Systems". World Food Prize International Intern in cooperation with the International Livestock Research Institute and Bureau of Agriculture, Wolayta Soddo.

Gebreegziabher Zereu and Tsegay Lijalem (2016), "Status of improved forage production, utilization and constraints for adoption in Wolaita Zone, Southern Ethiopia”. Livestock Research for rural Development 28(5).

Getnet A. (2012), "Retrospects and prospects of forage and pasture crop research in Ethiopia". In: Getnet Assefa, Mesfin Dejene, Jean Hanson, Getachew Anemut, Solomon Mengistu And Alemayehu Mengistu (eds), Forage seed research and development in Ethiopia. Ethiopia institute of agricultural research, Addis Ababa, Ethiopia. Pp 7-14.

ILRI (International Livestock Research Institute) (2010), "Production and Distribution Networks now Avail Forage Planting Materials to Smallholder Dairy Producers in East Africa": ILRI outcome story 2009. International Livestock Research Institute, Nairobi, Kenya.

Mekoya, Abebe., Oosting, S.J., Fernandez-Rivera, S. and Van der Zijpp, A.J.(2008), "Multipurpose fodder trees. Farmers' perception, constraints to adoption and effects of long-term supplementation on sheep performance".

Mengistu, A. (2002), "Forage production in Ethiopia: a case study with implications for livestock production. Forage production in Ethiopia: a case study with implications for livestock production".

Muhammad Zubair Anwar, M. Azeem Khan, Ikram Saeed, Akhtar Ali, Shafique Zahid and Abdul Majid (2012), "Small farmers perceptions regarding improved fodder and forage varieties: results of participatory on farm research". Pakistan J. Agric. Res. 25 (4).

Muluken Shiferaw, B imrew Asmare, Firew Tegegne, and Dessalen Molla (2018), "Farmers perception and utilization status of improved forages grown in the natural resource areas of northwestern Ethiopia". Biodiversitas Journal of Biological Diversity. 19 (4).

Othill JC. (1986), "Fodder and Forage Management for Small holder Mixed farms in the Ethiopian Highland". Paper presented at the ICIMOD conference on Mountain pasture and Fodder Management in the Hindu Kusha Region, Kathmandu, May, 25-31.

Robertson, A.D. (1990), "Final Report on Forage Development Activities and Proposals”. FLDP, Ministry of 
Agriculture, Ethiopia.

Teshome M. (2014), "Population growth and cultivated land in Rural Ethiopia: Land use dynamics, access, farm size, and fragmentation”. Resources and Environment 4(3): 148-161.

Tsige-Yohannes Habte (2000), "Livestock feed security and associated impacts on sustainable agricultural development". In: proceedings of the 7th annual conference of Ethiopian Society of Animal Production (ESAP), Addis Ababa, Ethiopia, 26-27 May. pp.51-61.

Workye et al. (2018), "Improved forage production practice and challenges in Libokemkem District, Ethiopia". Agricultural Research Communication Centre. Agric. Sci. Digest., 38(4): 280-284.

Zekarias Bassa (2016), "Determinants of Improved Forages Adoption in Doyogena District of Kembata Tembaro Zone, in Southern Nations, Nationalities Regional State, Ethiopia".

Zekarias Bassa and Teshale Woldeamanuel (2015), "Value chain analysis of the cattle trade in Moyale, southern Ethiopia: An economic assessment in Oromia Regional State”. IIED Country Report. IIED. 36p. 